\title{
The Specific Organism: Not Bacterial Gram Type: Drives the Inflammatory Response in Septic Shock
}

\author{
Adam Linder $^{\mathrm{a}}$ Chris D. Fjell ${ }^{\mathrm{b}}$ Malin Inghammar ${ }^{\mathrm{a}}$ Joseph $\mathrm{Hsu}^{\mathrm{c}}$ \\ Keith R. Walley ${ }^{b}$ John H. Boyd ${ }^{b}$ James A. Russell ${ }^{b}$

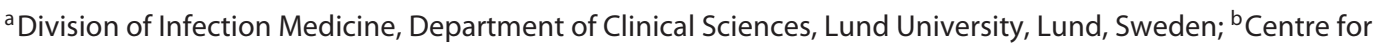 \\ Heart Lung Innovation and Division of Critical Care Medicine, St. Paul's Hospital, University of British Columbia, \\ Vancouver, BC, Canada; ' Pulmonary and Critical Care Medicine, Department of Medicine, Stanford University School \\ of Medicine, Stanford, CA, USA
}

\section{Keywords}

Septic shock · Organism • Pathogen - Gram type ·

Inflammation · Cytokines

\begin{abstract}
Background and Hypothesis: The inflammatory response was targeted by unsuccessful therapies but ignored pathogen. We hypothesized that the inflammatory response differs according to organism in human septic shock. Materials and Methods: We measured 39 cytokines at baseline and $24 \mathrm{~h}$ in patients $(n=363)$ in the Vasopressin and Septic Shock Trial (VASST). We compared cytokine profiles (cytokine functional class) at baseline and at $24 \mathrm{~h}$ by organism and used hierarchical clustering to classify cytokines according to 28-day outcomes. Results: In 363 patients, 88 and 176 patients had at least 1 species isolated from blood and other sites, respectively. Cytokine levels differed significantly according to organism: Neisseria meningitidis and Streptococcus pneumoniae had the highest (baseline and at $24 \mathrm{~h}$ ), while Enterococcus faecalis (blood) had the lowest mean cytokine levels. N. meningitidis and Klebsiella pneumoniae had significantly higher cytokine levels at baseline versus $24 \mathrm{~h}(p=0.01$ and 0.02 , re-
\end{abstract}

spectively); E. faecalis had significantly higher cytokine levels at $24 \mathrm{~h}$ versus baseline. Hierarchical clustering heat maps showed that pathogens elicited similar cytokine responses not related to the functional cytokine class. Conclusion: The organism type induces different cytokine profiles in septic shock. Specific gram-positive and gram-negative pathogens stimulated similar plasma cytokine-level patterns.

(c) 2019 The Author(s)

Published by S. Karger AG, Basel

\section{Introduction}

Septic shock is increasingly common with high, but declining short- [1] and long-term mortality rates [2]. Many different pathogens [3] cause septic shock, and organism type and site of infection may be an important determinant of outcome [4]. Recently, the prevalence of gram-positive bacteria has increased and is similar to or even higher [5] than the prevalence rate of gram-negative infections [6-8]. However, about two-thirds of patients with septic shock never have positive blood cultures and about one-third have no positive cultures from any site $[9,10]$.

\begin{tabular}{|c|c|}
\hline KARGER & $\begin{array}{l}\text { (c) } 2019 \text { The Author(s) } \\
\text { Published by S. Karger AG, Basel }\end{array}$ \\
\hline $\begin{array}{l}\text { E-Mail karger@karger.com } \\
\text { www.karger.com/jin }\end{array}$ & $\begin{array}{l}\text { This article is licensed under the Creative Commons Attribution- } \\
\text { NonCommercial-NoDerivatives } 4.0 \text { International License (CC BY- } \\
\text { NC-ND) (http://www.karger.com/Services/OpenAccessLicense). } \\
\text { Usage and distribution for commercial purposes as well as any dis- } \\
\text { tribution of modified material requires written permission. }\end{array}$ \\
\hline
\end{tabular}

Dr. Adam Linder

Division of Infection Medicine, Department of Clinical Sciences

Lund University, B14, Tornavägen 10

SE-221 84 Lund (Sweden)

E-Mail adam.linder@med.lu.se 
A meta-analysis of 510 studies found that gram-negative bacteremia was associated with a significantly higher mortality than gram-positive bacteremia [11], implying that organism gram type should be incorporated into the risk stratification of randomized controlled trials (RCTs) in septic shock. However, Zahar et al. [12] found no difference in mortality rates according to organism gram type.

Several physiological responses to infection in septic shock are similar according to gram type such as the hemodynamic response [13-15], but there is no correlation between the organism gram type and the presence or severity of sepsis-associated coagulopathy [16]. Therefore, 2 assumptions were often made: first, proinflammatory mediators were of similar importance in septic shock regardless of the gram type and, second, that inhibition of proinflammatory mediators in all patients, independent of infecting organism gram type, was unlikely to cause harm.

The host inflammatory response has been targeted by many unsuccessful therapies (e.g., anti-tumor necrosis factor [TNF] [17], TNF receptor [18], interleukin [IL]1ra [19], anti-IL-6, tissue factor pathway inhibitor [20]). However, different inflammatory response according to organism type could explain in part the lack of success of prior RCTs because prior RCTs targeted pooled patients regardless of organism. There are hints that organism type might be an important determinant and predictor of response to anti-inflammatory therapies. For example, p75 soluble TNF receptor treatment was efficacious in patients with gram-negative sepsis but possibly harmful in patients with gram-positive sepsis $[18,21]$, and corticosteroids, platelet-activating factor antagonists, and antiendotoxin therapies had some benefit in gram-negative sepsis but no effect in gram-positive sepsis [22].

Prior studies of gram types of organisms and the human host cytokine response (as reflected by plasma levels) are contradictory with studies showing both differences and similarities according to organism gram type [23-25] further clouding the interpretation of prior trials in which patients were pooled regardless of organism type. We hypothesized that the inflammatory response at baseline and at $24 \mathrm{~h}$ differs according to organism, as opposed to gram type, in patients with septic shock.

\section{Materials and Methods}

\section{Subjects}

The Vasopressin and Septic Shock Trial (VASST) [10] was a multicenter randomized double-blind controlled trial of vasopressin plus norepinephrine versus norepinephrine alone in septic shock (Current Controlled Trials number ISRCTN94845869). Eth- ics approval was obtained for the VASST study from the University of British Columbia/Providence Health Care Research Ethics Board. Written informed consent was obtained from all patients, their next of kin, or another surrogate decision maker. The VASST study enrolled 778 patients who were older than 16 years of age and had septic shock, defined by the presence of 2 or more systemic inflammatory response syndrome criteria [26], proven or suspected infection, new dysfunction of at least 1 organ, and hypotension despite adequate fluid resuscitation (lack of response to $500 \mathrm{~mL}$ normal saline) and requiring vasopressor support of at least $5 \mathrm{mg} / \mathrm{min}$ of norepinephrine (or equivalent) for $6 \mathrm{~h}$. Important exclusion criteria were unstable coronary syndromes, acute mesenteric ischemia, severe chronic heart disease (New York Heart Association class III and IV), and vasospastic diathesis. Of these patients, 363 had blood plasma samples taken at baseline (enrolment at a median of $12 \mathrm{~h}$ following meeting septic shock inclusion criteria) and $24 \mathrm{~h}$ later. Since we studied the impact of pathogens on the inflammatory response, we excluded patients who had negative cultures.

\section{Plasma Cytokine Assay}

In this study, we included patients for whom we had both baseline and 24-h plasma samples. A panel of 39 cytokines were measured in duplicate by Luminex MAG 39plex multiplex bead assay on a 100/200 System (Luminex Corporation, Austin, TX, USA) according to the manufacturer's specifications. Positive and negative controls were assayed on each plate. The cytokines measured were (using both current and historical naming) CCL11 (Eotaxin), CCL2 (MCP1), CCL22 (MDC), CCL3 (MIP1a), CCL4 (MIP1B), CCL7 (MCP3), CD40LG (CD40Ligand), CSF2 (GMCSF), CSF3 (GCSF), CX3CL1 (Fractalkine), CXCL1 (GRO), CXCL10 (IP10), EGF (EGF), FGF2 (FGF2), FLT3LG (Flt3L), IFNA2 (IFNa2), IFNG (IFNG), IL10 (IL10), IL12B (IL12B), IL12P70 (IL12P70), IL13 (IL13), IL15 (IL15), IL17A (IL17), IL1A (IL1a), IL1B (IL1B), IL1RN (IL1RA), IL2 (IL2), IL2RA (IL2RA), IL3 (IL3), IL4 (IL4), IL5 (IL5), IL6 (IL6), IL7 (IL7), IL8 (IL8), IL9 (IL9), LTA (TNFB), TGFA (TGFa), TNF (TNFA), and VEGFA (VEGF).

Values were reported by the assay system in $\mathrm{pg} / \mathrm{mL}$; these were converted to molar concentrations using Ensembl mature peptide amino acid sequences and molecular weights calculated using pepstats from the EMBOSS 4.1.0 software.

\section{Microbiology}

All culture results for the $48 \mathrm{~h}$ prior to and after inclusion in VASST as reported by each site's clinical microbiology laboratory were recorded. Organisms were classified as gram positive or negative according to conventional definitions.

\section{Statistical Methods}

Comparison of Cytokine Levels

All statistics were calculated using the base stats package of the R statistical language. Cytokine levels were compared using $t$ test with Welch's method for unequal variance ( $t$ test method). Multiple-comparison adjustment was done using false discovery rate (FDR) of Benjamini-Hochberg method, using $p$. adjust method; adjusted values are reported as $p_{\text {adj }}, p_{\text {adj }}<0.05$ was taken as significant. Cytokine levels were $\log 10$-transformed before comparison to make their distribution approximately normal. Cytokines with values of zero were assigned to $1 / 2$ the minimum cytokine level detected overall for any cytokine to allow logtransformation. 
Table 1. Demographics

\begin{tabular}{|c|c|c|c|}
\hline Variables & All patients & Blood culture positives & Other site culture positives \\
\hline Number & 363 & 88 & 176 \\
\hline Age, years, mean (SD & $63(50-72)$ & $62(50-72)$ & $62(50-72)$ \\
\hline Gender female, $n(\%)$ & $147(40)$ & $39(44)$ & $65(37)$ \\
\hline \multicolumn{4}{|l|}{ Comorbidities } \\
\hline Cong. heart failure, $n(\%)$ & $25(6.9)$ & $3(3.4)$ & $12(6.8)$ \\
\hline Renal failure, $n(\%)$ & $36(9.9)$ & $6(6.8)$ & $18(10)$ \\
\hline COPD, $n(\%)$ & $60(17)$ & $9(10)$ & $35(20)$ \\
\hline Malignancy, $n(\%)$ & $68(19)$ & $18(20)$ & $28(16)$ \\
\hline APACHE II, mean (SD) & $26(22-32)$ & $28(24-33)$ & $25(20-32)$ \\
\hline White blood cells, mean (SD) & $14(7.8-21.1)$ & $15(7.1-22.4)$ & $13(8-19)$ \\
\hline Lactate, $\mathrm{mmol} / \mathrm{L}$, mean (SD) & $1.7(0.8-3.6)$ & $2.2(1.2-4.7)$ & $1.5(0.0-2.9)$ \\
\hline MAP, mean (SD) & $72(67-78)$ & $72(68-77)$ & $72(67-78)$ \\
\hline Respiratory rate, mean (SD) & $19(15-24)$ & $19(15-23)$ & $19(14-25)$ \\
\hline Norepinephrine max dose day 1 , mean (SD) & $15(9-26)$ & $16(9.2-29.1)$ & $14(8-25)$ \\
\hline Pao2/Fio2 baseline, mean (SD) & $194(143-260)$ & $200(150-273)$ & $188(139-249)$ \\
\hline Site of infection lung, $n(\%)$ & $116(44.1)$ & $37(42.0)$ & $79(50.5)$ \\
\hline Site of infection abdominal & $69(26.2)$ & $17(19.3)$ & $52(29.5)$ \\
\hline Other site of infection & $73(27.8)$ & $31(35.2)$ & $42(23.9)$ \\
\hline Gram positive bacteria, $n(\%)$ & $121(46.4)$ & $51(58.0)$ & $70(39.8)$ \\
\hline Gram negative bacteria, $n(\%)$ & $79(33.8)$ & $33(37.5)$ & $46(26.1)$ \\
\hline Mixed, $n(\%)$ & $29(16.7)$ & $4(4.5)$ & $25(22.8)$ \\
\hline Fungi, $n(\%)$ & $24(9.1)$ & $4(5.4)$ & $20(11.4)$ \\
\hline 28-day mortality & $104(29)$ & $22(25)$ & $52(30)$ \\
\hline
\end{tabular}

MAP, mean arterial pressure; COPD, chronic obstructive pulmonary disease; gram-positive bacteria, Staphylococcus aureus, Staphylococcus epidermidis, Streptococcus pneumoniae, Streptococcus pyogenes, Group B Streptococci, Streptococcus species, Enterococcus faecalis, Propionibacteria, Clostridium; gram-negative bacteria, Escherichia coli, Klebsiella pneumoniae, Neisseria meningitidis, Enterobacteriaceae, Proteus mirabilis, Pseudomonas aeruginosa, Stenotrophomonas maltophilia, Bacteroides fragilis.

For clustering, the hclust method was used for hierarchical clustering with method parameter = complete and euclidean dissimilarity matrix using transformed cytokine concentrations. Visualization was done with heatmap function. The $t$ test for comparison of subgroups used Welch's method as above.

We also separated the 39 different cytokines into 6 groups according to their proposed mode of action as described by us previously $[27,28]$.

\section{Results}

\section{Patient Demographics and Microbiology}

Patients were typical of septic shock (e.g., mean age 63 years, predominantly male [60\%]; Table 1). The most common site of infection was the lungs followed by abdomen in both patients with positive blood cultures and positive cultures at other sites, and gram-positive bacteria were more commonly isolated than gram-negative bacteria (Table 1). Of the 363 patients, 264 patients $(72.7 \%)$ had at least 1 organism isolated from at least 1 site. Of these, 88 patients (33.3\%) had at least 1 organism isolated from blood and 176 (66.7\%) had at least 1 organism isolated from other sites, such as urine, sputum, and wounds. In the remaining analyses, culture-negative patients $(n=99)$ were excluded.

There were no significant differences between patients with positive blood cultures and patients with positive cultures from other sites except for APACHE II and lactate. The most common bacteria in the positive blood culture group were S. aureus, Escherichia coli, and Streptococcus pneumoniae. 
Fig. 1. a Forest plot showing the distribution of baseline mean normalized (SEM) cytokine levels according to organism isolated in blood or from other sites. The overall mean normalized cytokine level was set at 0.0. N. meningitidis isolated from other sites had the highest and enterococci isolated in blood had the lowest mean cytokine levels, respectively. b Forest plot showing the distribution of mean normalized (SEM) cytokine levels at $24 \mathrm{~h}$ according to organism isolated in blood or from other sites. c Forest plot showing the distribution of mean normalized baseline and $24 \mathrm{~h}$ cytokine levels according to organism isolated in blood or from other sites. Red and black squares represent baseline and $24 \mathrm{~h}$ samples, respectively. $p$ values are shown for the comparison of the baseline with the $24 \mathrm{~h}$ mean normalized cytokine levels after FDR correction.

Inflammatory Response in Septic Shock Is Dependent on the Organism
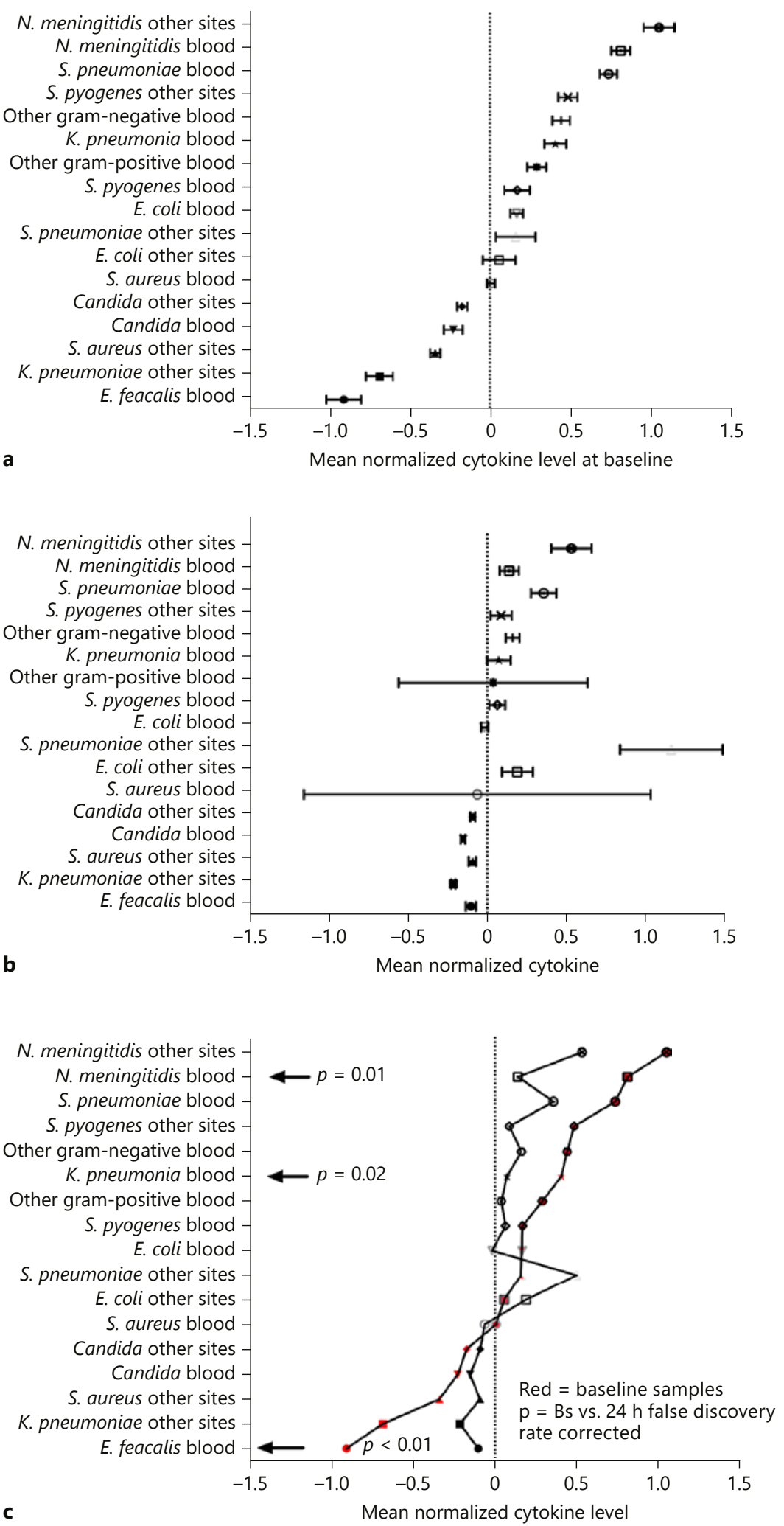

C 


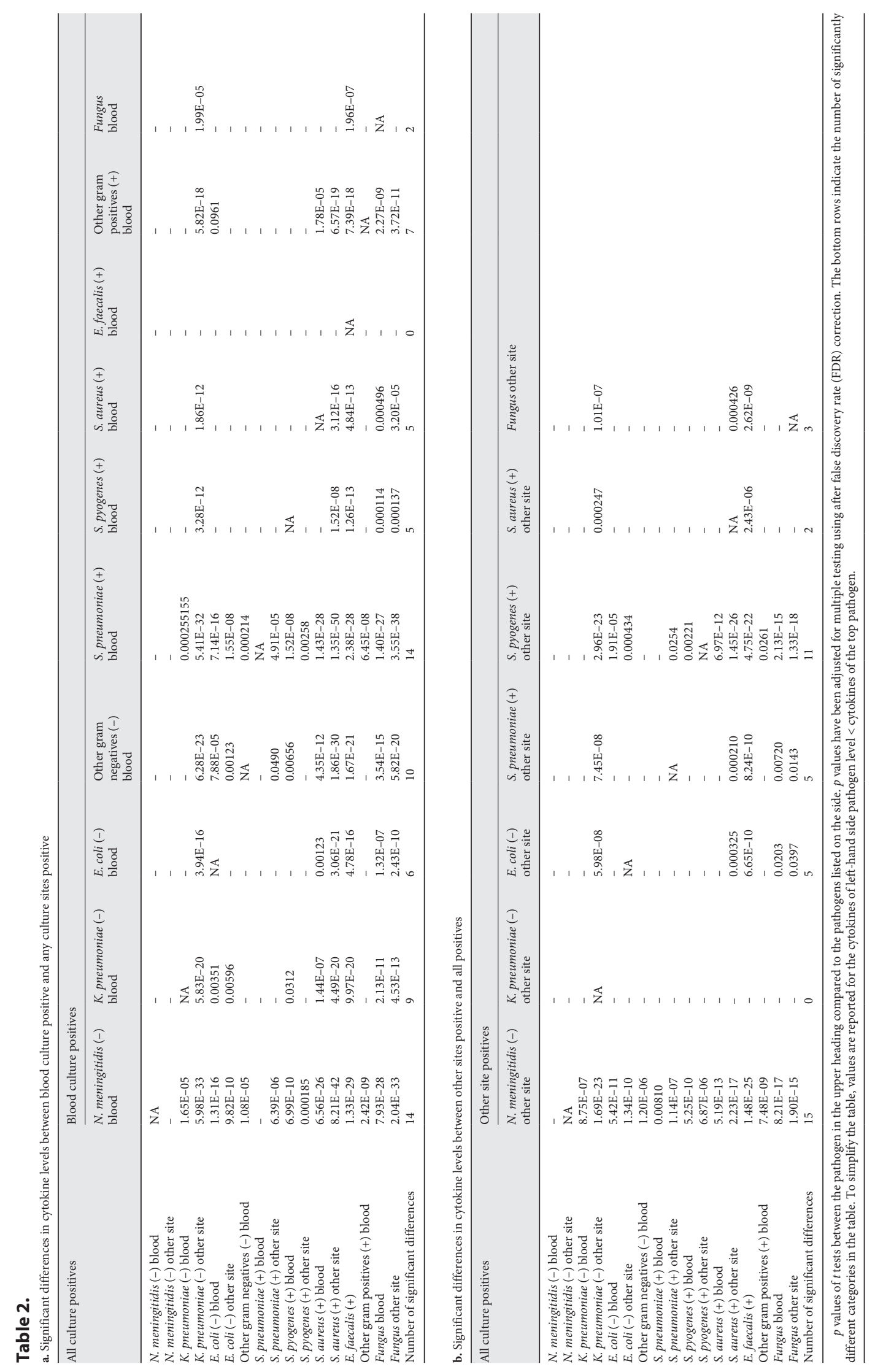


Fig. 2. Heat maps with cytokines classified into 6 functional groups showing blood culture at baseline. Red denotes higher and yellow denotes lower plasma mean normalized cytokine levels. Other+, indicates gram-positive organisms other than $S$. pneumonia, S. aureus, S. pyogenes, and $E$. faecalis. Other-, indicates gram-negative organisms except N. meningitidis, E. coli, and K. pneumoniae. The number of isolates for each pathogen isolated from blood was Candida $n=9, S$. aureus $n=25, S$. pyogenes $n=7$, S. pneumonia $n=9$, Other $\mathrm{G}+n=3$, E. $\operatorname{coli} n=17$, K. pneumonia $n=7$, N. meningitidis $n=4$, and Other $\mathrm{G}-n=7$.

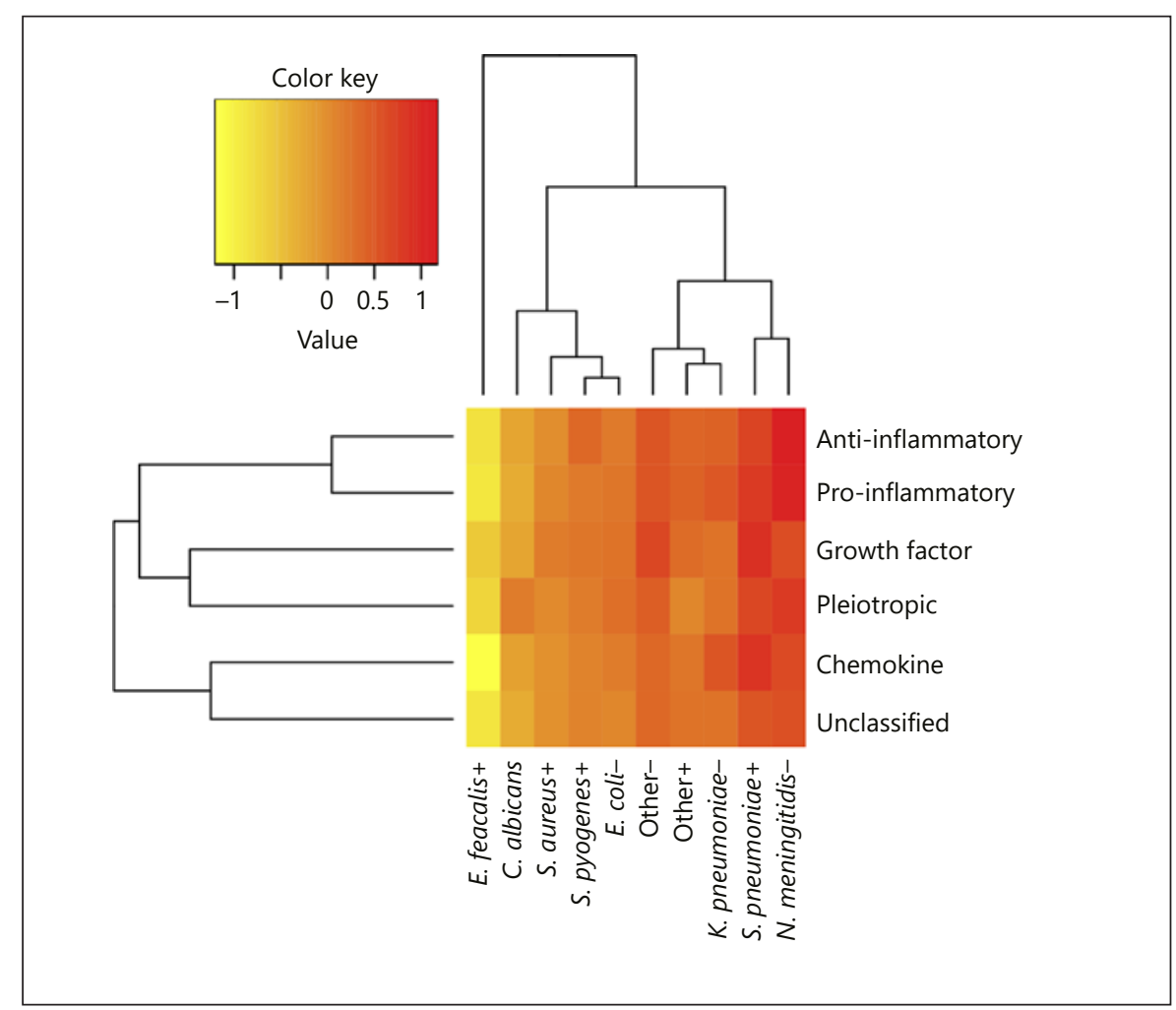

Plasma Cytokine Levels at Baseline and $24 \mathrm{~h}$ According to Organism

Patients with the gram-negative Neisseria meningitidis $(n=7)$ and the gram-positive S. pneumoniae $(n=20)$ isolated from blood had the highest mean cytokine levels both at baseline and at $24 \mathrm{~h}$ (Fig. 1a, b). Patients with the gram-positive Enterococcus faecalis $(n=7)$ and the fungus Candida species $(n=19)$ in blood cultures had the lowest mean cytokine levels. Of the 8 different pathogens isolated from blood, patients with all but E. faecalis and Candida had higher mean cytokine values at baseline compared to at $24 \mathrm{~h}$ (Fig. 1c). Of the patients with gramnegative pathogens, patients who had $N$. meningitidis and Klebsiella pneumonia $(n=18)$ isolated had significantly higher cytokine levels at baseline compared to at $24 \mathrm{~h}$ ( $p_{\text {adj }}=0.01$ and 0.02 , respectively). In contrast, patients with $E$. faecalis isolated had significantly lower cytokine levels at baseline versus $24 \mathrm{~h}\left(p_{\text {adj }}<0.01\right)$.

Different organisms had significantly different cytokine levels (Table 2a, b); in these tables, the results of comparisons of 2 groups are shown (top category vs. side category) with number of significant differences in the bottom row. For example, patients with cultures positive for $K$. pneumoniae had significantly lower cytokine levels than N. meningitidis in blood ( $p_{\text {adj }}=1.65 \mathrm{E}-5$, first column third row of Table 2a). Patients with N. meningitidis and $S$. pneumoniae isolated from blood had significantly higher mean normalized cytokine levels compared to all other pathogens isolated from blood or other sites except for N. meningitidis isolated from sputum (N. meningitidis, other site Table $2 \mathrm{~b}$ ).

\section{Plasma Cytokine Clusters According to Organism}

Heat maps were constructed that showed that different organisms of the same gram type elicited very different cytokine responses that did not cluster together (Fig. 2a, online suppl. Fig. 1a-c, for all online suppl. material, see www.karger.com/doi/10.1159/000500418). We found 2 larger clusters in both blood and other sites at baseline and $24 \mathrm{~h}$ (Fig. 2a, online suppl. Fig. 1a-c). The gram-negative $N$. meningitidis elicited the highest response and clustered with the gram-positive $S$. pneumoniae when isolated from blood cultures (Fig. 2a, online suppl. Fig. 1a). In blood and other culture sites, E. faecalis and Candida consistently had the lowest cytokine responses.

The 39 cytokines were separated into 6 groups according to their proposed mode of action $[27,28]$. Pro- and anti-inflammatory cytokines clustered together at base- 
line and at $24 \mathrm{~h}$ (Fig. 2a, online suppl. Fig. 1a-c) with the exception that Streptococcus pyogenes $(n=6)$ switched to the high cytokine cluster trading place with K. pneumoniae (Fig. 2a, online suppl. Fig. 1a-c).

In blood cultures, N. meningitidis and S. pneumoniae plasma cytokine levels were significantly higher than all other species, while E. faecalis had significantly lower plasma cytokine levels compared to all other organisms in blood or other sites overall (Table $2 \mathrm{a}$ ).

\section{Discussion}

We found that the inflammatory response at baseline and at $24 \mathrm{~h}$ differed according to organism, as opposed to gram type, in patients with septic shock, both among organisms isolated from blood or from other sites in patients who had septic shock. N. meningitidis, S. pneumonia, and K. pneumoniae elicited the highest inflammatory response as indicated by significantly higher plasma cytokine levels; the gram-positive E. faecalis, the gram-negative E. coli, and the fungus Candida were associated with the lowest plasma cytokine levels. Furthermore, the inflammatory response at baseline in patients with positive blood cultures clustered into 2 distinct groups of high and low plasma cytokine levels. For most organisms, the baseline plasma cytokine levels were higher than at $24 \mathrm{~h}$ except for E. faecalis in blood and S. aureus and K. pneumoniae from other sites.

Surprisingly, the cytokine response was very similar in gram-positive and gram-negative organisms. All organism types are ligands for various Toll-like receptors that signal comparable inflammatory responses. Gram-positive organisms activate the immune system through TLR2 , whereas gram-negative organisms stimulate TLR-4 [29]. Our findings suggest that there is another more level of organism-specific control of the inflammatory response in septic shock as assessed by plasma cytokines because we found significant differences in the inflammatory response according to specific organism.

The cytokine responses differed between patients with positive blood versus other culture sites. One possible explanation is that blood culture positivity elicits a different immune response because of the need for a more rapid and potent sustained response than when organisms are not present in blood. Another possible explanation is that the organisms isolated from other nonblood sites were not infecting pathogen but were colonizing organisms.

Plasma cytokine levels were higher at baseline and decreased by $24 \mathrm{~h}$ for most organisms (except for E. faecalis in blood and S. aureus and K. pneumoniae from other sites), aligning with our prior finding that survivors have greater decreases of cytokine levels than nonsurvivors $[27,28]$.

Our findings that gram type is not associated with the level of inflammatory response are consistent with studies showing that there were no differences between patients with gram-positive versus gram-negative infections and the presence of sepsis-associated coagulopathy [16].

Strengths of our study include the multicenter design, a large sample size, detailed microbiology results from clinical laboratories (a feature of pragmatic design), measurement of 39 plasma cytokines, chemokines, and growth factors, and use of hierarchical and functional cytokine class clustering.

There are limitations of our study. First, we did not measure organism load and that could have differed according to specific organism, thereby altering the rate and degree of cytokine response. Second, we used clinically available cultures from the clinical sites in VASST and that adds some variability in terms of both when cultures were taken (this was not protocolized) and laboratory procedures for organism detection. The study is retrospective, and we did not have access to the information on the clinical judgment whether a pathogen was considered relevant or not and we did not have information regarding initial adequate antimicrobial treatment and source control. Another limitation is that sicker patients have higher cytokine levels independent of organism or that patients who have community-acquired sepsis (e.g., N. meningitidis) have higher cytokine levels and are seen earlier in their illness. In the VASST study, there was community- and hospital-acquired sepsis, but the current study was not adequately powered to analyze these subgroups further. We have not analyzed or evaluated the issue of mixed isolates herein because we were interested in the individual organism associations with outcomes. Finally, we do not have specific information on the laboratory methods for microbial diagnostics which were the standard accredited clinical hospital laboratory methods at each site.

Also, we measured plasma cytokines at baseline and at $24 \mathrm{~h}$, so our interpretations are limited to early responses in plasma according to organism in septic shock. We measured 39 cytokines in plasma at baseline and at $24 \mathrm{~h}$ so cannot imply associations of organism and other inflammatory markers at later time points. Despite our large sample size, the subgroups of organism type were too small to assess the relationship of specific organism and mortality. 
In conclusion, the inflammatory response at baseline and at $24 \mathrm{~h}$ in human septic shock differed according to organism, as opposed to gram type. Patients with septic shock display unique early cytokine profiles according to organism type but not gram type. The gram-negative $N$. meningitidis, the gram-positive S. pneumonia, and the gram-negative $K$. pneumoniae elicited the highest cytokine responses. In contrast, the gram-positive E. faecalis, the gram-negative E. coli, and the fungus Candida were associated with the lowest plasma cytokine levels. Larger trials that modulate the inflammatory response in septic shock may benefit by evaluating the therapies in subgroups according to the specific organism rather than according to organism gram type.

\section{Acknowledgments}

We thank the patients and families who participated in the VASST study, which has increased our understanding of the treatment of septic shock. We also thank the many dedicated clinicians (doctors, nurses, therapists, and others) who cared for these critically ill patients and comforted their families.

\section{Appendix}

In addition to the authors, the following persons and institutions participated in the VASST trial: Writing Committee: J.A. Russell (chair), K.R. Walley, A.C. Gordon, C. Holmes Boulton, J.T. Granton, P.C. Hebert, D.J. Cooper, S. Mehta, J. Singer, D.J. Cook, J.J. Presneill, M.M. Storms; Executive Committee: J.A. Russell (chair), K.R. Walley, C.L. Holmes Boulton, J.T. Granton, P.C. Hebert, D.J. Cooper, S. Mehta, J. Singer, A.C. Gordon, M.M. Storms (project coordinator), S. Jones (administrative assistant); Management Committee: J.A. Russell (chair), M.M. Storms (project coordinator), K.R. Walley, C.L. Holmes Boulton, J. Singer, A.C. Gordon, S. Jones (administrative assistant); DSMB: G.R. Bernard (chair), A.S. Slutsky, G.A Wells; CIHR: A. Gasparini; Data Management: J. Singer, B. Savage, D. Ayers, R. Woods, K. Wu, M. Maralit; Monitoring: L. Smith, K. Foley, A. Suri, M. Steinberg, B. Howe, P. Galt, A. Higgins, M.M. Storms; Laboratory: M.E. LeBlanc, A.M. Sutherland, A. Sham, A. McLeod.

Clinical Centers and VASST Investigators: Canada, British Columbia; St. Paul's Hospital - J.A. Russell, K.R. Walley, D.R. Dorscheid, M. Hameed, L. Lazosky, S. Helderweirt, K. Foley, C. Honeyman, T. Terins; Vancouver General Hospital - D. Chittock, J. Ronco, L. Smith, S. Logie; Royal Jubilee Hospital - G. Wood, F. Auld; Kelowna General Hospital - C. Holmes Boulton, V. Stedham, M. Mantle, L. Fox, G.D. McCauley, J.D. Rolf, C. Erbacher; Richmond General Hospital - G. Martinka, S. Goulding, S. Silverwood, L. Leung; Royal Columbian Hospital - S. Keenan, J. Murray, M. Van Osch. Manitoba; St. Boniface Hospital - B. Light, M. Dominique; Winnipeg Health Science Centre - P. Gray, R. Stimpson, S. Rosser, D. Bell, W. Janz. Ontario; Ottawa Hospital, General Campus - P.C. Hebert, T. McArdle, I. Watpool; UHN - Toronto Gen- eral \& Toronto Western Hospitals - J.T. Granton, M. Steinberg, A. Matte-Martyn; St. Joseph's Hospital - D.J Cook, E. McDonald, F. Clarke, A. Tkaczyk, N. Zytaruk; Mount Sinai Hospital - S. Mehta, T. Stewart, A. Suri, C. Martinez-Motta, R. MacDonald, V. Sivanantham; Ottawa Hospital, Civic Campus - R. Hodder, J. Foxall, M. Lewis; St. Michael's Hospital - M. Ward, C. Dos Santos, J. Friedrich, D. Scales, O. Smith, I. DeCampos, A. Richards, H. Michalopoulos, U. Bakshi; Sunnybrook and Women's College Health Science Centre - W. Sibbald (deceased), T. Smith, K. Code, B. Bojilov, C. Dale, M. Keogh; Hamilton Health Sciences Centre - M. Meade, L. Hand; London Health Sciences Centre - C. Martin, J. Kehoe, V. Binns; Sudbury Regional Hospital - M. Mehta, M. McGuire; Charles LeMoyne Hospital - G. Poirier, L. Provost; Windsor - Hotel Dieu Hospital - J. Muscedere, C. Diemer. Australia: Victoria; Alfred Hospital - D.J. Cooper, V. Pellegrino, A. Hilton, S. Morrison, C. Weatherburn, K. Moulden, C. Harry; Royal Melbourne - J.J. Presneill, M.S. Robertson, J.F. Cade, B.D. Howe, D.K. Barge, C.A. Boyce, F. Healy; Monash Medical Center - C. Wright, D. Weyandt, J. Barrett, C. Walker, P. Galt, S. Burton. Western Australia; Royal Perth Hospital - G. Dobb, S. Perryman, J. Chamberlain, L. Thomas. South Australia; Flinders Medical Centre, A. Bersten, L. Daly, T. Hunt, D. Wood. USA: Mayo Hospital - B. Patel, J. Larson, M. Rady, G. LeBrun, E. Boyd, R. Rush.

\section{Disclosure Statement}

Dr. James A. Russell reports patents owned by the University of British Columbia (UBC) that are related to PCSK9 inhibitor(s) and sepsis and related to the use of vasopressin in septic shock. Dr. James A. Russell is an inventor on these patents. Dr. James A. Russell is a founder, director, and shareholder in Cyon Therapeutics Inc. (developing a sepsis therapy (PCSK9 inhibitor)). Dr. James A. Russell has share options in Leading Biosciences Inc. Dr. James A. Russell is a shareholder in Molecular You Corp. Dr. James A. Russell reports receiving consulting fees in the last 3 years from: Asahi Kesai Pharmaceuticals of America (AKPA; developing recombinant thrombomodulin in sepsis). La Jolla Pharmaceuticals (developing angiotensin II; Dr. Russell chaired the DSMB of a trial of angiotensin II from 2015 to 2017) - no longer actively consulting. Ferring Pharmaceuticals (manufactures vasopressin and was developing selepressin) - no longer actively consulting. Cubist Pharmaceuticals (now owned by Merck; formerly was Trius Pharmaceuticals; developing antibiotics) - no longer actively consulting. Leading Biosciences (was developing a sepsis therapeutic that is no longer in development) - no longer actively consulting. Grifols (sells albumin) - no longer actively consulting. CytoVale Inc. (developing a sepsis diagnostic) - no longer actively consulting. Dr. James A. Russell reports having received an investigator-initiated grant from Grifols (entitled "Is HBP a mechanism of albumin's efficacy in human septic shock?") that is provided to and administered by UBC.

The other authors have no conflicts of interest. 


\section{References}

1 Kaukonen KM, Bailey M, Suzuki S, Pilcher D, Bellomo R. Mortality related to severe sepsis and septic shock among critically ill patients in Australia and New Zealand, 2000-2012. JAMA. 2014 Apr;311(13):1308-16.

2 Linder A, Guh D, Boyd JH, Walley KR, Anis AH, Russell JA. Long-term (10-year) mortality of younger previously healthy patients with severe sepsis/septic shock is worse than that of patients with nonseptic critical illness and of the general population. Crit Care Med. 2014 Oct;42(10):2211-8.

3 Angus DC, Linde-Zwirble WT, Lidicker J, Clermont G, Carcillo J, Pinsky MR. Epidemiology of severe sepsis in the United States: analysis of incidence, outcome, and associated costs of care. Crit Care Med. 2001 Jul;29(7): 1303-10.

4 Roberts FJ, Geere IW, Coldman A. A threeyear study of positive blood cultures, with emphasis on prognosis. Rev Infect Dis. 1991 JanFeb;13(1):34-46.

5 Vincent JL, Rello J, Marshall J, Silva E, Anzueto A, Martin CD, et al.; EPIC II Group of Investigators. International study of the prevalence and outcomes of infection in intensive care units. JAMA. 2009 Dec;302(21):2323-9.

6 Finfer S, Bellomo R, Lipman J, French C, Dobb G, Myburgh J. Adult-population incidence of severe sepsis in Australian and New Zealand intensive care units. Intensive Care Med. 2004 Apr;30(4):589-96.

7 Brun-Buisson C, Doyon F, Carlet J; French Bacteremia-Sepsis Study Group. Bacteremia and severe sepsis in adults: a multicenter prospective survey in ICUs and wards of 24 hospitals. Am J Respir Crit Care Med. 1996 Sep; 154(3 Pt 1):617-24

8 Vincent JL, Sakr Y, Sprung CL, Ranieri VM, Reinhart K, Gerlach H, et al.; Sepsis Occurrence in Acutely Ill Patients Investigators. Sepsis in European intensive care units: results of the SOAP study. Crit Care Med. 2006 Feb;34(2):344-53.

9 Rangel-Frausto MS. The epidemiology of bacterial sepsis [vii.]. Infect Dis Clin North Am. 1999 Jun;13(2):299-312.

10 Russell JA, Walley KR, Singer J, Gordon AC, Hébert PC, Cooper DJ, et al.; VASST Investigators. Vasopressin versus norepinephrine infusion in patients with septic shock. N Engl J Med. 2008 Feb;358(9):877-87.
11 Cohen J, Cristofaro P, Carlet J, Opal S. New method of classifying infections in critically ill patients. Crit Care Med. 2004 Jul;32(7):151026.

12 Zahar JR, Timsit JF, Garrouste-Orgeas M, Français A, Vesin A, Descorps-Declere A, et al. Outcomes in severe sepsis and patients with septic shock: pathogen species and infection sites are not associated with mortality. Crit Care Med. 2011 Aug;39(8):1886-95.

13 Ahmed AJ, Kruse JA, Haupt MT, Chandrasekar PH, Carlson RW. Hemodynamic responses to gram-positive versus gram-negative sepsis in critically ill patients with and without circulatory shock. Crit Care Med. 1991 Dec;19(12):1520-5.

14 Wiles JB, Cerra FB, Siegel JH, Border JR. The systemic septic response: does the organism matter? Crit Care Med. 1980 Feb;8(2):55-60.

15 Natanson C, Danner RL, Elin RJ, Hosseini JM, Peart KW, Banks SM, et al. Role of endotoxemia in cardiovascular dysfunction and mortality. Escherichia coli and Staphylococcus aureus challenges in a canine model of human septic shock. J Clin Invest. 1989 Jan; 83(1):243-51.

16 Levi M, van der Poll T. Coagulation in sepsis: all bugs bite equally. Crit Care. 2004 Apr;8(2): 99-100.

17 Reinhart K, Menges T, Gardlund B, Harm Zwaveling J, Smithes M, Vincent JL, et al. Randomized, placebo-controlled trial of the anti-tumor necrosis factor antibody fragment afelimomab in hyperinflammatory response during severe sepsis: the RAMSES Study. Crit Care Med. 2001 Apr;29(4):765-9.

18 Fisher CJ Jr, Agosti JM, Opal SM, Lowry SF, Balk RA, Sadoff JC, et al.; The Soluble TNF Receptor Sepsis Study Group. Treatment of septic shock with the tumor necrosis factor receptor:Fc fusion protein. N Engl J Med. 1996 Jun;334(26):1697-702.

19 Fisher CJ Jr, Dhainaut JF, Opal SM, Pribble JP, Balk RA, Slotman GJ, et al. Recombinant human interleukin 1 receptor antagonist in the treatment of patients with sepsis syndrome. Results from a randomized, doubleblind, placebo-controlled trial. Phase III rhIL1 ra Sepsis Syndrome Study Group. JAMA. 1994 Jun;271(23):1836-43.
20 Abraham E, Reinhart K, Opal S, Demeyer I, Doig C, Rodriguez AL, et al.; OPTIMIST Trial Study Group. Efficacy and safety of tifacogin (recombinant tissue factor pathway inhibitor) in severe sepsis: a randomized controlled trial. JAMA. 2003 Jul;290(2):238-47.

21 Zeni F, Freeman B, Natanson C. Anti-inflammatory therapies to treat sepsis and septic shock: a reassessment. Crit Care Med. 1997 Jul;25(7):1095-100.

22 Opal SM, Cohen J. Clinical gram-positive sepsis: does it fundamentally differ from gram-negative bacterial sepsis? Crit Care Med. 1999 Aug;27(8):1608-16.

23 Fisher CJ Jr, Opal SM, Dhainaut JF, Stephens $S$, Zimmerman JL, Nightingale P, et al. Influence of an anti-tumor necrosis factor monoclonal antibody on cytokine levels in patients with sepsis. The CB0006 Sepsis Syndrome Study Group. Crit Care Med. 1993 Mar;21(3): $318-27$.

24 Opal SM, Garber GE, LaRosa SP, Maki DG, Freebairn RC, Kinasewitz GT, et al. Systemic host responses in severe sepsis analyzed by causative microorganism and treatment effects of drotrecogin alfa (activated). Clin Infect Dis. 2003 Jul;37(1):50-8.

25 Cohen J, Abraham E. Microbiologic findings and correlations with serum tumor necrosis factor-alpha in patients with severe sepsis and septic shock. J Infect Dis. 1999 Jul;180(1): 116-21.

26 Bone RC, Balk RA, Cerra FB, Dellinger RP, Fein AM, Knaus WA, et al.; The ACCP/ SCCM Consensus Conference Committee. American College of Chest Physicians/Society of Critical Care Medicine. Definitions for sepsis and organ failure and guidelines for the use of innovative therapies in sepsis. Chest. 1992 Jun;101(6):1644-55.

27 Fjell CD, Thair S, Hsu JL, Walley KR, Russell JA, Boyd J. Cytokines and signaling molecules predict clinical outcomes in sepsis. PLoS One. 2013 Nov;8(11):e79207.

28 Russell JA, Fjell C, Hsu JL, Lee T, Boyd J, Thair $\mathrm{S}$, et al. Vasopressin compared with norepinephrine augments the decline of plasma cytokine levels in septic shock. Am J Respir Crit Care Med. 2013 Aug;188(3):356-64.

29 Boyd JH. Toll-like receptors and opportunities for new sepsis therapeutics. Curr Infect Dis Rep. 2012 Oct;14(5):455-61. 